\title{
An Application of Lean Manufacturing Techniques in Paint Manufacturing Company: A Case Study
}

\author{
Ahmed M. Badeeb, Reda M.S. Abdulaal and Abdullah O. Bafail \\ Industrial Engineering Department, Faculty of Engineering, King Abdulaziz University، Jeddah, \\ Saudi Arabia \\ eng.abadeeb@hotmail.com
}

\begin{abstract}
As a result of the recession in Saudi Arabia, the manufacturing companies start thinking to reduce the operational cost and increasing the productivity through lean manufacturing principles. This paper is focused on increasing the productivity of a paint manufacturing company through implementing some of the lean manufacturing techniques. First, Value stream mapping analysis carried on throughout the manufacturing process and the areas of improvements in the company has been identified using fishbone diagram. Second, Work Place Organization (5S), Single Minute Exchange of Dies (SMED), Work Standardization and Kanban are the lean manufacturing techniques selected to solve different problems facing the company in these areas of improvements. A systematic approach of each technique implemented to measure its effect on the company productivity. It is observed that, applying (5S) and (SMED) techniques in the filling process decreased the changeover time by $59 \%$ and increased the daily productivity. Pareto chart recommended using work standardization in the charging process led to reduce the defects batches by $57 \%$. Kanban system eliminated the shortages of semi-finish product and increased the output of the pre-weighing batches by $57 \%$. In addition, overtime hours reduced by $77 \%$ and waste handling reduced by $85 \%$ and $53 \%$ for the non-hazardous and hazardous waste respectively.
\end{abstract}

Keywords: Paint manufacturing, Lean manufacturing techniques, Single minute exchange of dies, Work place organization (5S) technique, Value stream mapping.

\section{Introduction}

Paints manufacturing companies in Saudi Arabia grew rapidly in the last few decades because of a boost in the national economy due to high prices of oil, which led to flourishing projects in both government and private sectors. Companies, during this period reached to their highest level of performance in all aspects, like products, sales, revenues and profit. Unfortunately, when the oil prices decreased globally in the last two years (20162017) so rapidly that it reached its lowest level in the year 2016 due to various reasons. This decrease affected the global economy, especially the countries that highly depend on oil production. As a result of which, the industrial sector was affected negatively including the paint manufacturing companies. Management teams started thinking of increasing the production and decreasing the waste in order to overcome this tough period and continue its growth. Lean manufacturing techniques are suitable for such a period where there is no much need to invest in new 
technology or human's resources. Identifying the bottlenecks around the manufacturing process will help a lot to reduce the waste and the unnecessary tasks performed by the workers. Selecting the suitable lean manufacturing techniques and applying it in the highly affected area could reduce waste and increase the production ${ }^{[1]}$. The next sections, of this paper, will illustrate the main principles of lean manufacturing and its application in one of the leading Saudi paint manufacturing companies followed by the results and conclusions from real case study.

\section{LIterature Review}

The concept of lean starts when Toyota first introduced and implemented the Toyota Production System which is identified as the "origin" of lean ${ }^{[2]}$. Lean thinking considers things that the customer does not pay for a waste, while Lean manufacturing is an operational system that eliminates wastes and saves time for the manufacturing company. According to Wang ${ }^{[3]}$, many companies are trying to apply lean principles due to economic issues in the current world. Earlier, people lacked the knowledge to embrace lean manufacturing in their companies but now people have come to realize that lean manufacturing plays a critical role in reducing waste when combined with other resources of production ${ }^{[4]}$. Lean is aimed to bring overall change in a manufacturing plant rather than changing some few aspects within the organization [5]. Many lean tools and techniques applied in paint manufacturing companies such as Work Place Organization (5S), Single Minute Exchange of Dies (SMED), Work Standardization, and Kanban.

\subsection{Workplace Place Organization (5S)}

A good workplace organization is paramount to ensure there is an easy operation within the workstation ${ }^{[6]}$. The workplace place organization (5S) method serves very important functions in an organization that wants to cut unwanted production cost and improve the company's production. This method ensures every activity in the right order within the working environment. The technique supports other techniques like Just in Time (JIT) and Total Quality Management (TQM). The 5S notation comes from implementing five processes successively in the work place titled: Sort, Set in order, Shine, Standardize, and Sustain ${ }^{[7]}$. A clean environment ensures that the whole process of production is carried out smoothly and that is shine ${ }^{[8,9]}$.

\subsection{Single Minute Exchange of Dies (SMED)}

SMED is one of the various techniques used in the process of industrial manufacturing. It usually looks to reduce the time taken to accomplish changeover in equipment. Changeover time usually hides waste in the form of motion, transportation, waiting, defects and overproduction. SMED is best implemented when the teams that are involved in changeovers individually responsible for a specific machine ${ }^{[10]}$. It is powerful technique to reduce the waste in processing activities and to make improvements within the immediate time possible ${ }^{[11]}$. The details of the changeover process are marked and external activities separated from each other ${ }^{[12,13]}$.

\subsection{Work Standardization}

These are guidelines in lean management whereby procedures to be followed during production process are drawn ${ }^{[14]}$. The aim of work standardization is to make sure all the employees/workers can perform a specific task or carry on a long process from (a) to (z) correctly and as per the required quality. Standard form of work standardization firstly creates and then applies to all tasks. The form should be as simple as possible. 


\subsection{Kanban System}

Kanban basically as a lean manufacturing system that controls inventory and the supply chain purposely to improve efficiency. The implementation process of Kanban is a bit discouraging. However, Kanban is incremental and improve as time goes by. Changes are made when it happens and the initial steps are the most important one. Building a Kanban board is usually the second step in Kanban implementation ${ }^{[15]}$. The main principles that should be followed during the implementation of Kanban include visualization of workflow, limiting the issues being worked on, and optimizing the cycle time ${ }^{[16]}$.

\section{Stages of Paint Manufacturing}

One of the biggest Saudi companies, as a leader in paints manufacturing industries, wants to tackle the bottlenecks in the manufacturing process and increase the productivity. Lean manufacturing principles adopted to achieve the company's goals. A study team is formed to identify the bottlenecks in the manufacturing process, evaluate the problem and then suggest suitable lean techniques to implement. The study team divided the manufacturing process into four stages, which are: (1) Pre-weighing stage, (2) Charging stage, (3) Laboratory stage, and (4) Filling stage. The team has decided to ignore the laboratory stage and focus their efforts and studies on the other three stages as it has more potential for improvement. A process flow chart was conducted on each stage in order to illustrate the current process flow sequence followed by value stream mapping for the complete manufacturing process excluding Laboratory stage.

\subsection{Pre-weighing Process}

The pre-weighing process is simply where the raw materials are pre-weighed in order to start the manufacturing process. The Raw Material (RM) is divided into two categories:

- Fast and common raw material: These raw materials are always available in the shop floor and the operators will do the preweighing themselves as instructed in the charging recipe.

- Slow moving raw materials: These raw materials are pre-weighed in the raw material store just to ensure the exact quantity are given as per the recipe and it will be kept on a pallet waiting for the call from the shop floor operator.

- The daily capacity of the production department is to make an average of 24 batches. Once a filling process is completed, the charging operator will ask the forklift operator to bring the pre-weighted material from the raw material store for the next batch (Fig. 1).

\subsection{Charging Process}

The charging process is a core of the manufacturing process where the raw material is being charged to the dissolver in order to make the assigned product. It is called as charging process because the operators will start charging the raw material one by one to the dissolver or the mixer. As mentioned in pre-weighing step, once the filling process complete the charging operator will give a signal to the forklift operator to deliver the next pre-weighing batch to the shop floor. Once it reaches, the charging process will start. The first step of the charging process is to inspect the tank condition, according to the next desired product to be manufactured, the operator will decide whether the tank needs to be cleaned or not. If the tank is ready for charging, the first RMs to be added is the water and the binder from the Programmable Logic Controller (PLC) room. The addition of these RMs will occurred automatically through 
pipes, which are connected directly to the dissolver. The extenders will be added one by one using the help of stacker and fixed crane (fixed crane is available in each dissolver) where the stacker will be used to transfer the extenders which come in a bag of $1000 \mathrm{~kg}$, and the crane will lift the bag and put it closer to the manhole. Once the addition of the extenders is completed, the operators will preweigh the next additives, which are placed in cubic plastic tanks with a valve and a weighing scale. The additive will be mixed with water before adding it to the dissolver.
After the mixing time is completed, it will be added through big pots into the dissolver. Upon the completion of the mixing process, a sample of the paint will be taken in order to test the grinding stage on a paper panel. A 200 Micron will be applied on the panel and then will be kept inside an oven for an average of 20 minutes. If the grinding test passed, then another sample will be submitted to the lab in order to inspect the other specifications, such as the viscosity, PH-value, hiding power and the application structure (Fig. 2).

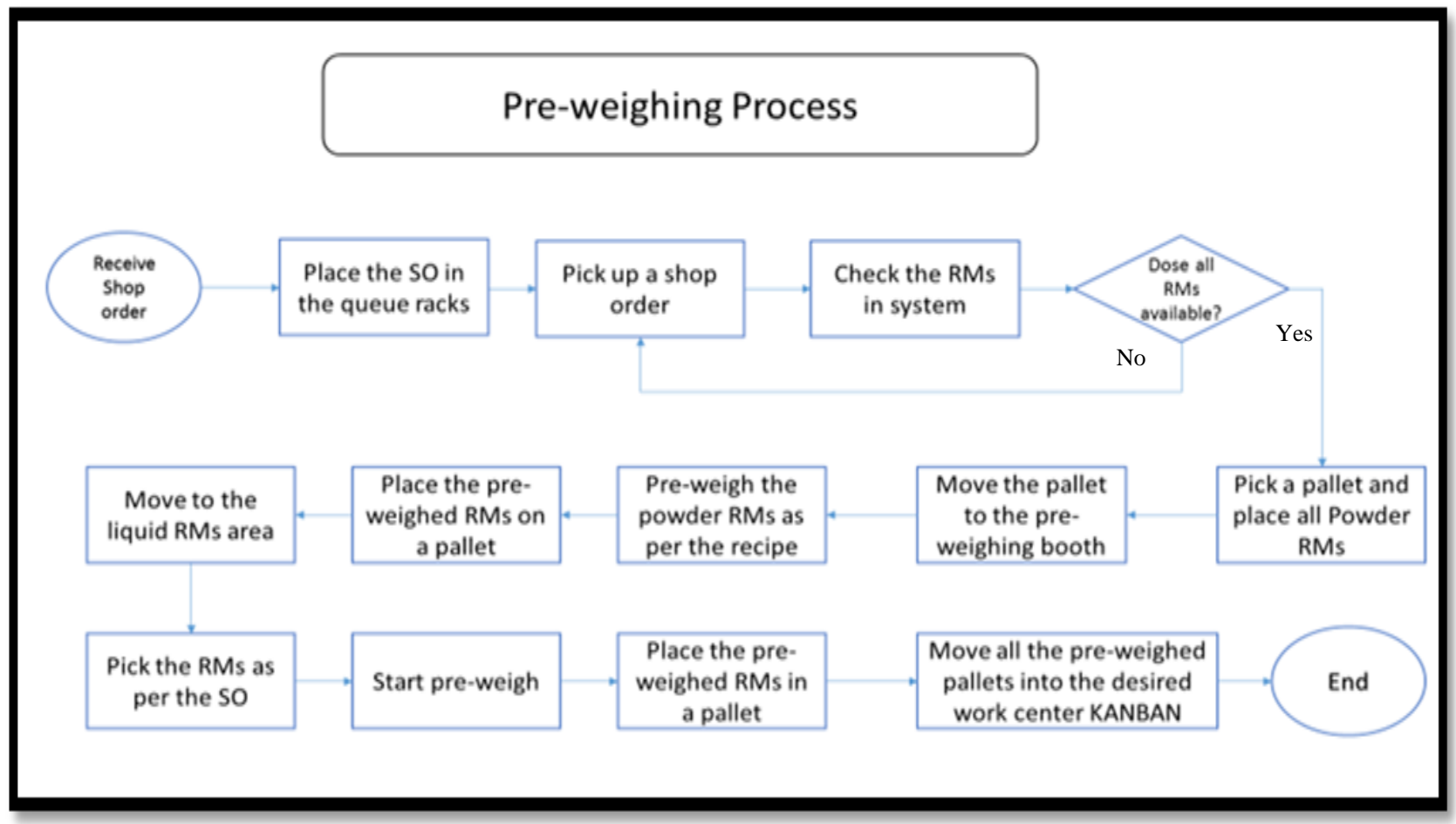

Fig. 1. The implementation steps of pre-weighing process.

\subsection{Filling Process}

Filling process is the last main process in the manufacturing whole process. The filling process comes exactly after the approval of the item under charging. Laboratory will give green signal to the production operators to start filling process (i.e. once the submitted sample meets the corporate specification range). Filling process is containing the following small tasks:

- Define the net weight and gross weight for the batch to be filled (operator not lab).

- Arrangement of packing materials. (KANBAN)

- Arrangement of empty pallets. 
- Labelling of packing materials. (One piece flow)

- Feeding packing materials into the filling line.
- Start filling

- Placing the drums into pallet

- Moving the full pallets into the temporary storage area.

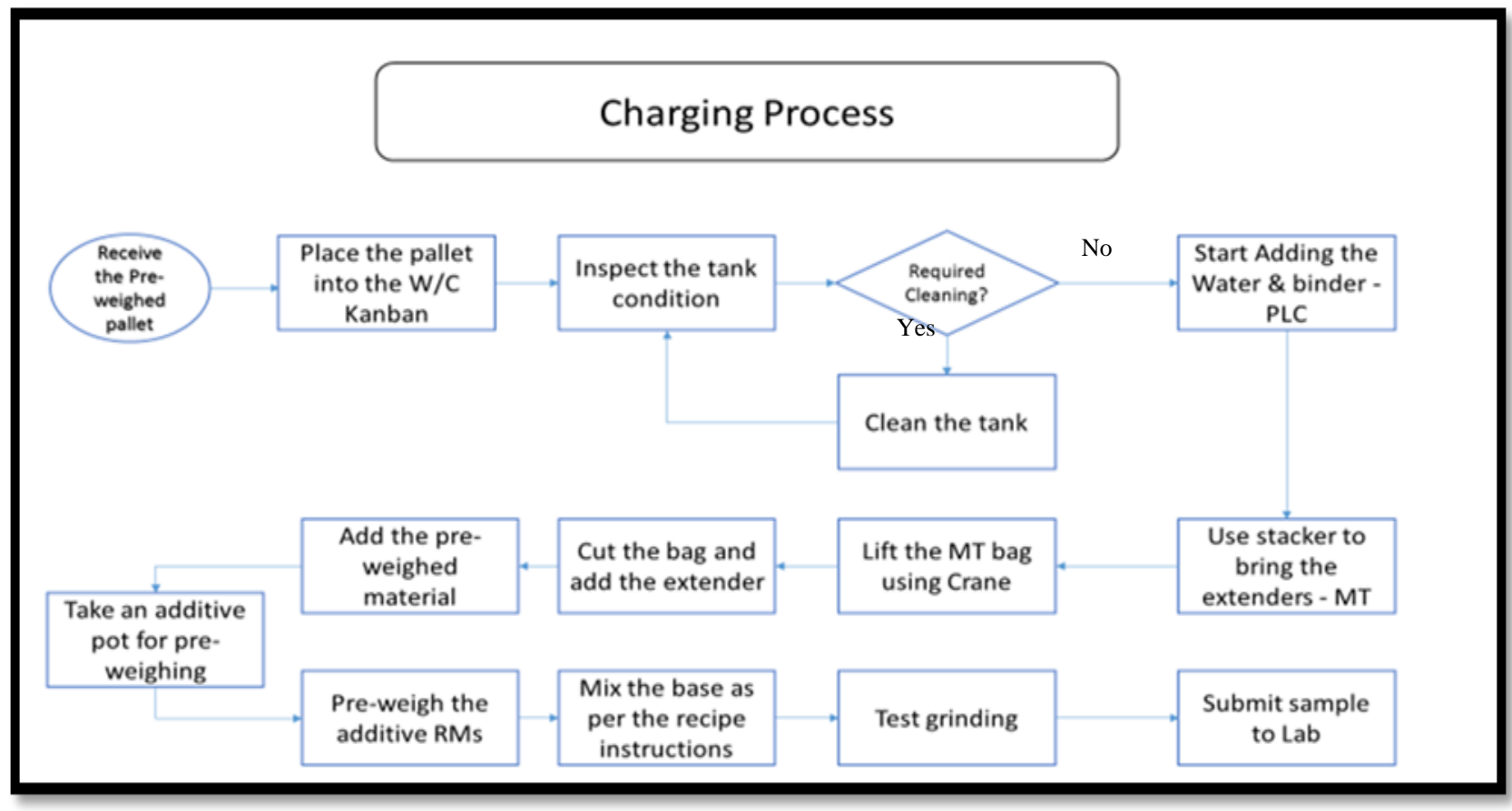

Fig. 2. The implementation steps of charging process.

The lab team will decide the net weight and gross weight according to the approved batch's specific gravity and density. All the tasks described above carried out manually except the filling of paint into the pails. The arrangement of packing materials, empty pallets and moving the pallets into the temporary storage area carried out using stackers for transferring. Placing the pails into the pallets is semi-auto task where an operator will use air lifter machine that sucks the pail's top and then placing it into the pallets, where a worker operates the air lifter machine. The number of the filling operators varies according to the production line capability and the packing size to be filled (i.e. small, medium and large packs). Labelling process is fully a manual task where the filling operators will past the label on each pail manually. According to several process observations for the three stages of the manufacturing process, the filling process is the longest process in most of the products. Figure 3 illustrates the filling process.

\section{The Proposed Methodology}

The formed study team recommended using some of lean manufacturing techniques to increase the company's productivity. The team starts with data collection followed by data analysis and ends with implementing four lean manufacturing techniques.

\subsection{Data Collection}

Value Stream Mapping (VSM) technique is used to collect the data for the 
completely manufacturing process to identify the waste sources and the area of improvement. The total water base production lines are 13 and thus, the focus was on the fast moving production line. As the overall process of manufacturing paints is similar in term of activities required to carry out the whole manufacturing process. Figure 4, explain the value stream mapping which the team has conducted for one production line that is consider as the most utilized production line. The team conducted observation for the manufacturing process several times and the findings below are the average result.

The total manufacturing time is equal 300 minutes $\approx 5$ hours where the value-added process time is 219 minutes while the nonvalue added time is equal to 88 minutes. The goal is to reduce the non-value added time and thus reducing the total manufacturing process time. The outcomes of the VSM can be summarized in the following points:
Pre-weighing Process:

- Pre-weighing Cycle time per batch: 25 min

- Number of batches pre-weighed per shift: 19 batches

- Total waiting time (non-value added): 8 $\min$

- Total Movement time (non-value added): $6 \mathrm{~min}$

- Total non-value added time: $14 \mathrm{~min}$

- Total value added time: 11 min

- Pre-weighing process Takt time (based on 32 batches): $15 \mathrm{~min} / \mathrm{batch}$

Charging and Filling Process:

- Charging process cycle time: $125 \mathrm{~min}$

- Filling Process Cycle time: $150 \mathrm{~min}$

- Total Waiting time (non-value added): 30 $\min$

- Total Movement time (non-value added): 25 $\min$

- Total non-value added time: $55 \mathrm{~min}$

- Total value added time: $220 \mathrm{~min}$

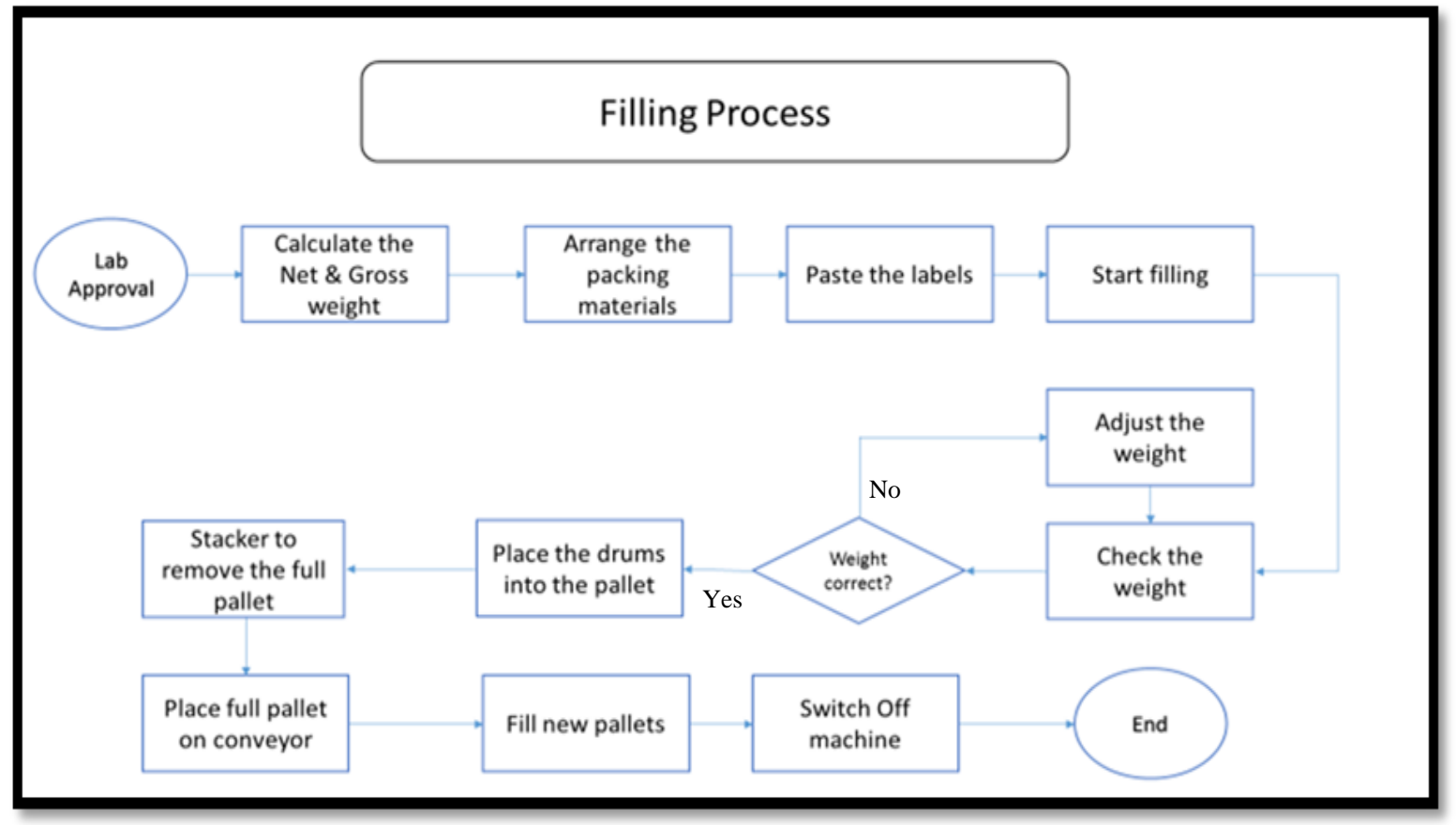

Fig. 3. The implementation steps of filling process. 


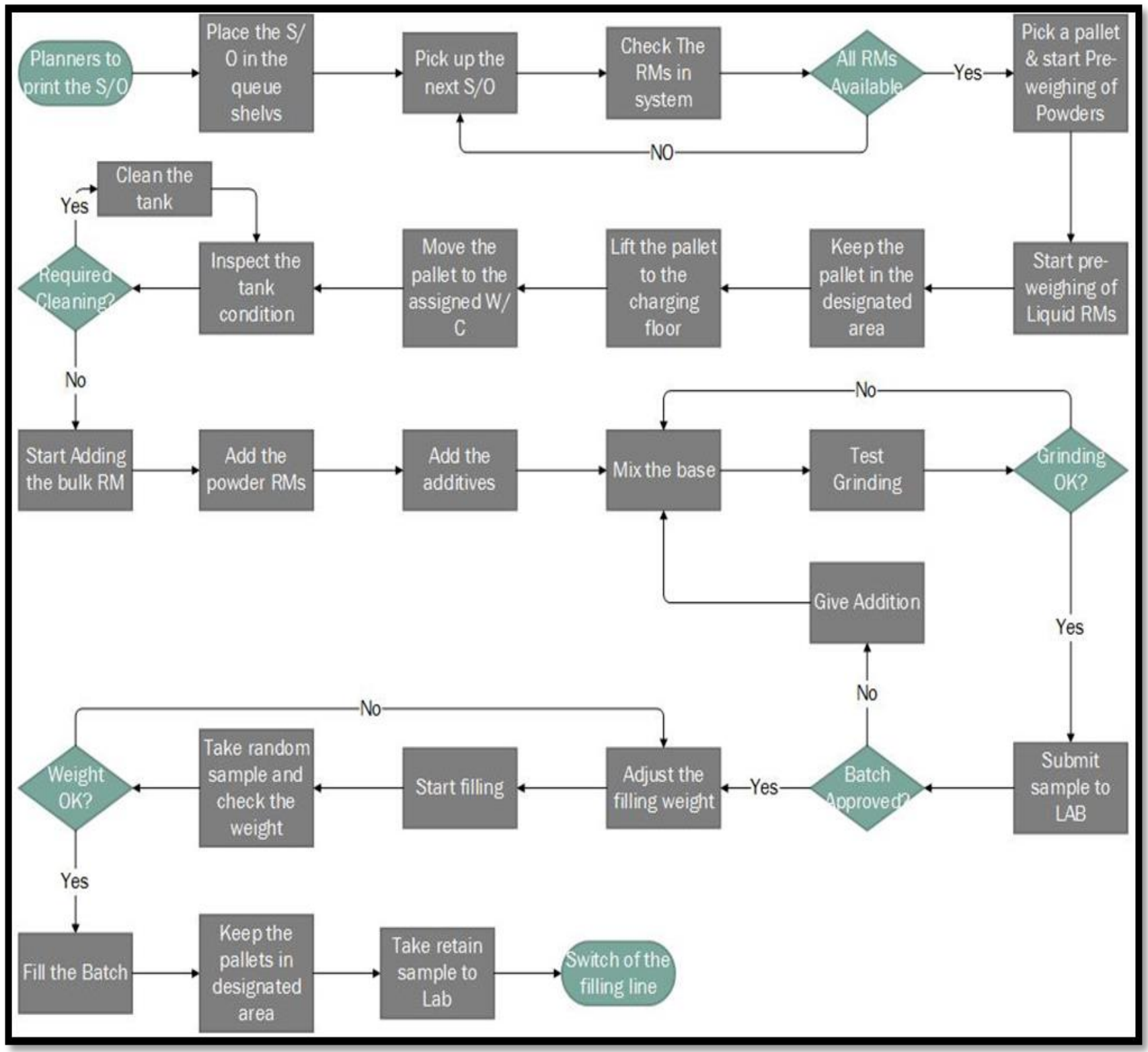

Fig. 4. Steps of Value Stream Mapping.

\subsection{Data Analysis}

Identifying Bottlenecks, is a process or operation that is less than average pace of the other process/operations in the same sequence. The following points were taken, as the most area, which needs for improvement (based on brainstorm session):

- Number of batches pre-weighed per shift
- Changeover time

- Waiting for shop orders to start preweighing

- Time consumed by movement in charging process

- Waiting for packing material during filling 
- Operators skills and knowledge of certain process/task

- Stoppage of production due to shortage of semi-finish RM

Fishbone diagram created to clarify and present the main root causes that affect the productivity and the waste management. In general, Fishbone diagram is a tool used to identify the causes and contributors to a specific problem. The team members came up with many causes for each category. The breakdown of production filling line is one of the causes that lie under the machine category. The productivity is also affected by the skills of the operators who are running the machine. Operator's skills lie under the category of people and so on (Fig. 5).

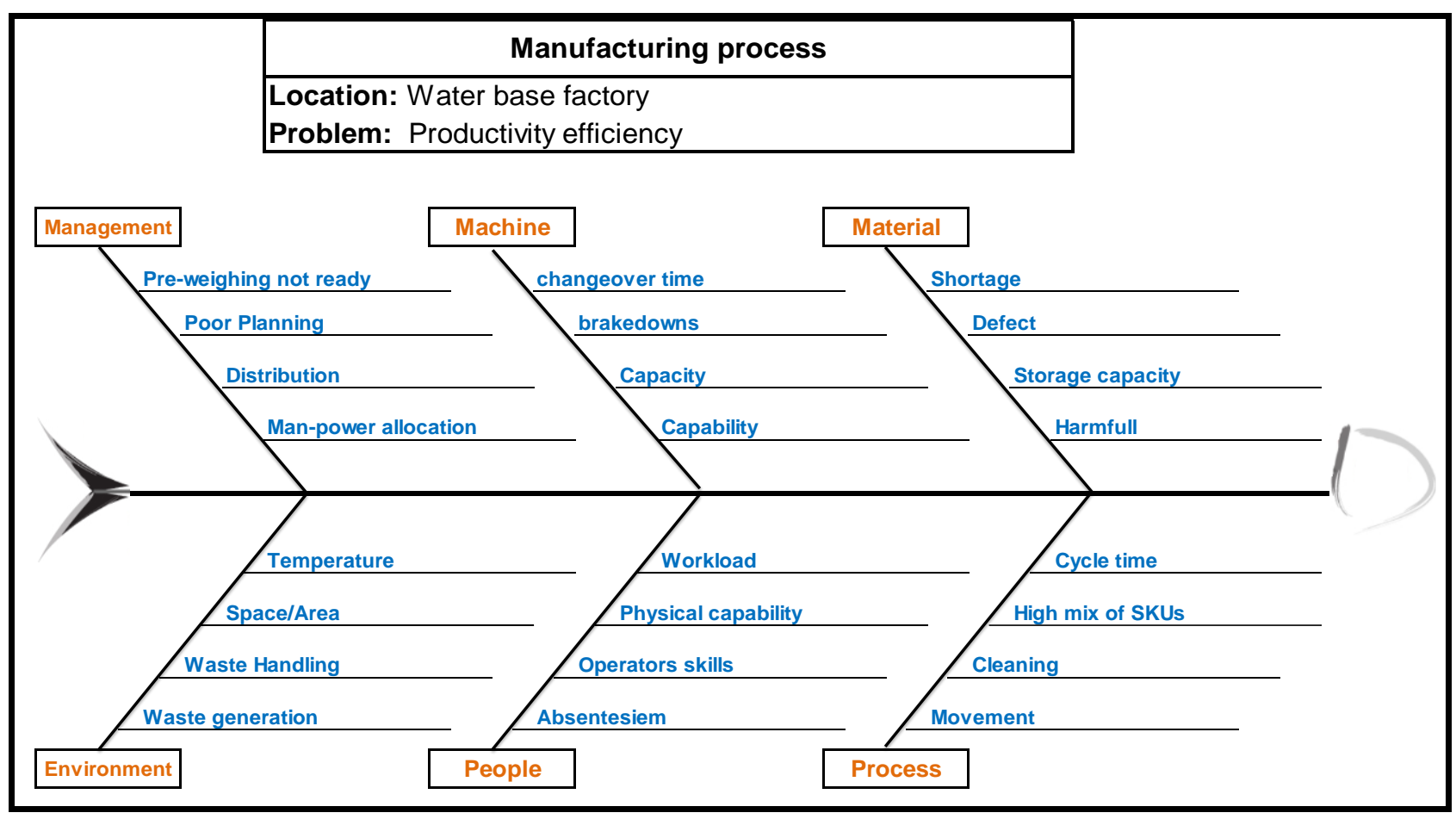

Fig. 5. Fishbone for the case under study.

Two brainstorming sessions have conducted. The first one is to find out what is the area of improvement for each of the three stages of the manufacturing process (i.e. increase the number of pre-weighed batches per shift). The second session performed to find out what are the best possible solutions that can affect achieving the defined improvements. The overall goal is to increase the productivity, reduce workload and better management of waste. Below listed are suggestive improvements:
- Increase the number of pre-weighed batches per shift

- Reduce the movement for pre-weighing and charging process

- Reduce the waste generation during filling process

- Reduce the cycle time for the preweighing and charging process

- Reduce the non-value added tasks

- Eliminate the production stoppage due to RM shortage 
- Reduce the changeover time for the filling process

- Reduce the human mistakes due to lack of skills or knowledge

- Reduce the workload on operators

\subsection{Lean Implementation}

Four lean manufacturing techniques selected as the most appropriate in order to achieve the company's goals and to increase the productivity:

- Work place Organization, $5 \mathrm{~s}$

- Single minute exchange of dies, SMED

- Work Standardization

- Kanban

\section{Results and Discussions}

\subsection{The Results Obtained Using Workplace Organization Technique (5S)}

The impact of implementing 5S technique in the raw material store and the pre-weighing area was significant. The team has changed the location of several raw materials and defined a location for all the tools and equipment's. The unwanted or expired raw material was removed from the place, which was making noise and delaying the movement of the workers in the area. Unnecessary tools such as cleaning tools, unused weighing scales and defected trolleys were sent to scrap after the approval of area owner. Paper handling was further improved where a shelf of multiple racks were fixed on the wall, and marked for each work center. All the shop orders for a certain W/C placed in its designated rack according to the sequence and priority (need date). The waste was eliminated. The following paragraphs show the area improved by applying $5 \mathrm{~S}$ technique and its impact on the production productivity.

Trolleys and stackers become easy to accessible and to find (Fig. 6). Designated place made to keep all the trolleys and stackers. This step organizes the place and let workers perform their tasks much way easier and faster than before. The huge impact of defining a designated place for the stackers and trolleys in the pre-weighing area occurred as the travel distance by the pre-weighing operators reduced. Pre-weighing operators become able to perform their task efficiently and consistent.

Each product in the production floor has its own filling size and correspondingly has its own layout for filling. So, having one filling line for different products a complex process and leads to time-consuming for the preparation of the layout especially when the area is congested. Operators usually take long time for moving the filling line to the desired layout so they can start filling. The team has sort the area and the filling line according to the size of packing to be filled. After several meetings and GEMBA (A Japanese word that literally means "the real place", used in business process improvement contexts to refer to the place where value is added, such as a manufacturing area or a workshop) on site they have decided a standard layout for each filling size of the packing material. They came up with 3 standard layouts for small, medium, and large packs. After finalizing the standard layouts, the layout for each size of packs marked using yellow tape as illustrated in Fig. 7.

In Fig. 8, the filled finish goods are placed on pallets waiting to be transferred to the conveyor by stackers. For each filling line, the area of placing the pallets has been marked. This step of making designated area for the filled pallets help the filling team to better organize the filling floor and it gives better reading for the supervisors. In addition, it worked like a Kanban for the pallets as the stacker operator can see that the designated area for a specific filling line is full of pallets and thus he has to drive the stacker and move the pallets to the conveyor. In fact, even safety 
has been considered by marking the specific area for the pallets, where there will be no misplacement of pallets on the emergency lines or green path allowing the operators to move smoothly to the fire assembly point when fire alarm starts.

During preventive maintenance or any breakdown, maintenance team or senior operators have to bring their own tools and equipment to fix the problem that is consuming time of movement. Several meetings held with the maintenance team and they have concluded that only specific tools are necessary to fix $80 \%$ of any breakdown of machine or to complete the preventive maintenance job. Tools has been provided to each machine whether its filling line or dissolver or any other machinery that operated by workers. Tools have been kept in toolbox nearby each machine and the keys kept with the team leader (Fig. 9).

Figure 10 shows the different raw materials in the raw material store and the preweighing area. The area has fully reorganized and the raw materials have been placed in a way that reduces the movement of workers. In addition, designated line made for each raw material to ease the process of reading the area and easily caught any shortages or near to shortage of raw material.

Future plan is to set re-order point for each line to better read the area and control the stock of the raw material.

Waste generation and treatment are costing the company a lot of money. The generated waste is divided into two categories that are hazardous waste and non-hazardous waste. Hazardous waste includes any waste that have contaminated by paint or any chemicals, while the non-hazardous waste is mostly the paper bags, plastics, uncontaminated packing material, nylons, etc. All stages of manufacturing generated waste that needs to be collected and sent to the designated area.

Previous practice shows that types of non-hazardous waste were collected in big cartons. After that, they placed on pallets in order to send to the non-hazardous huge waste trash. Whenever the trash bin reaches to certain limit, the HSE (Healthy, Safety, and Environment) team will call the non-hazardous agent to visit the factory and remove all the non-hazardous waste. The company has to pay the agency per kilograms. HSE team has made several visits to different agency dealing with the non-hazardous waste and agreed with one agency to take the non-hazardous waste with no cost if segregated properly. The agency and the company agreed to divide the waste into three main categories that are:

- Plastic waste (Nylons, paper cups, etc.)

- Packing material

- Jumbo and paper bags

The team has created new trash bins nearby workstations (Fig. 11), and ask the operators and cleaners to segregate the waste once it generated immediately so no need to accumulate all the waste and then segregated on the site as expected to take long time. Figure 11 shows the types of waste bins crated by the team where the blue bins made for the nylons bags and the green bins for the paper bags.

Segregating the waste according to the new three categories described above, the waste handling become easier and the cost of handling the hazardous and non-hazardous waste decreased due to the changes in the disposing methodology where before the nonhazardous waste being collected by a supplier, the company has to pay the supplier for taking the non-hazardous waste. However, the team members were able to find a contractor who has willingness to buy the waste if properly 
segregated (i.e. cartons, plastic, nylons etc.). So, the company has to stop paying the contractor for removing the waste and the opposite scenario occurred where the contractor pay the company for the waste he takes. In addition to the non-hazardous waste, the amount of the hazardous waste reduced due to the implementation and the close monitoring of the hazardous waste collected. The team has reinforced the differences between the hazardous waste and nonhazardous waste and the cost of treating each kind, the $5 \mathrm{~s}$ teams stopped the wrong behavior of putting a non-hazardous waste into the hazardous waste area and causing the contractor to ask for more money, which is of waste money company is paying. Table 1 and Fig. 12 illustrate the waste disposal progress.

Table 1. Monthly waste disposal in 2017.

\begin{tabular}{|c|c|c|}
\hline Month & Hazardous waste (KG) & $\begin{array}{c}\text { Non Hazardous } \\
\text { waste(KG) }\end{array}$ \\
\hline January & 6542 & 24090 \\
\hline February & 5990 & 22368 \\
\hline March & 6503 & 21951 \\
\hline April & 14151 & 21824 \\
\hline May & 7002 & 21782 \\
\hline June & 3207 & 15549 \\
\hline July & 5988 & 23960 \\
\hline August & 6221 & 21780 \\
\hline September & 5240 & 21220 \\
\hline October & 5650 & 23100 \\
\hline November & 6833 & 24772 \\
\hline December & 3122 & 3200 \\
\hline
\end{tabular}
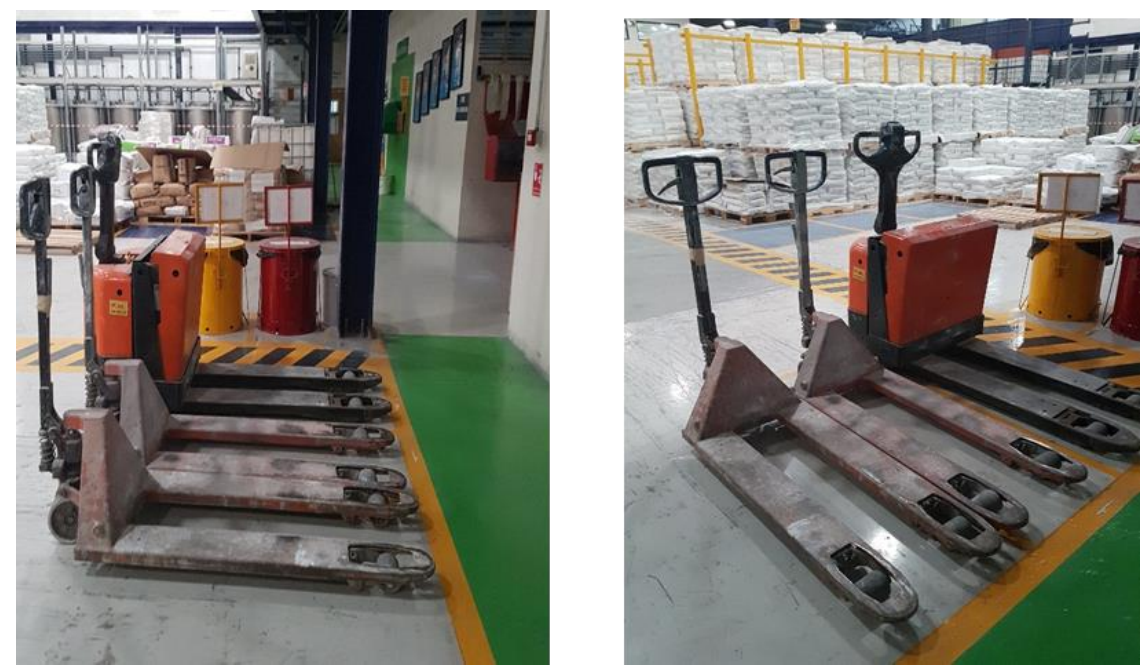

Fig. 6. Designated place for all trolleys and stackers in the pre-weighing area.
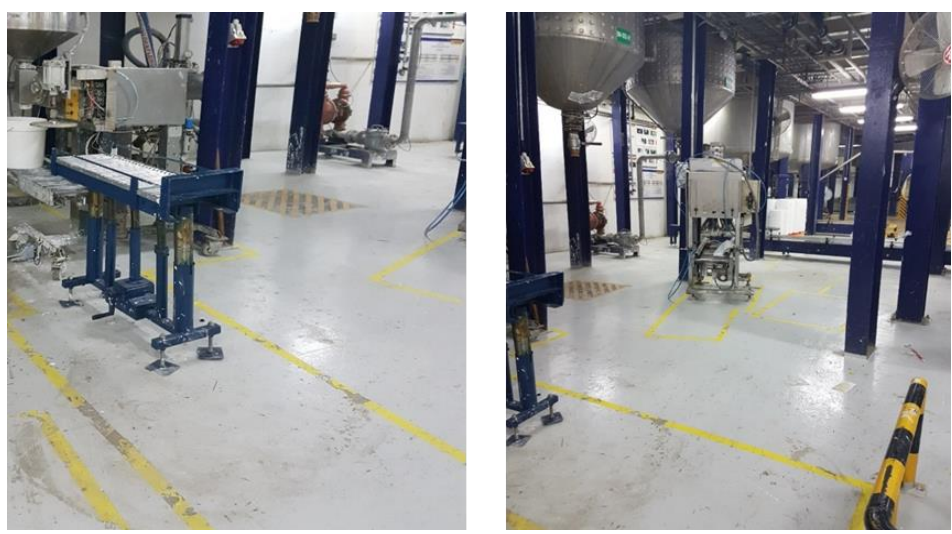

Fig. 7. Floor marked as per the filling size packing. 

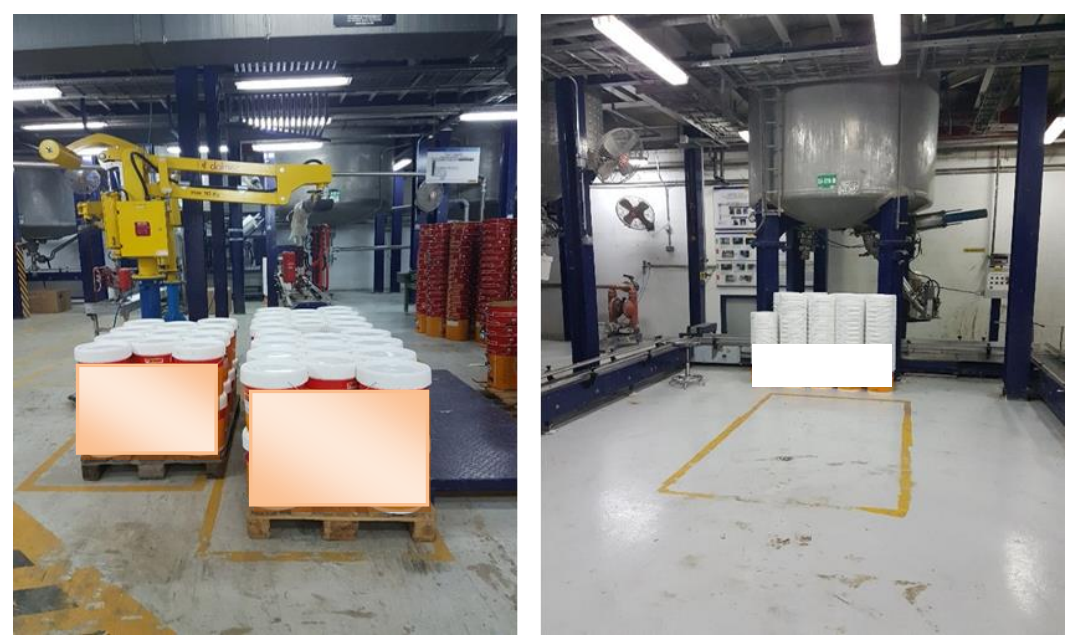

Fig. 8. Area marked for filled pallets.
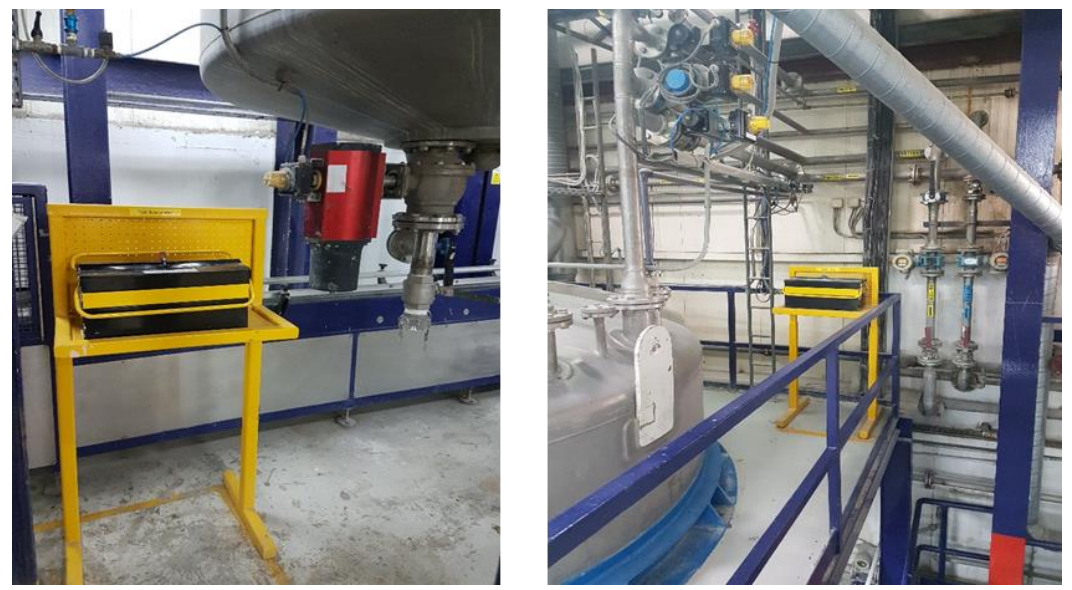

Fig. 9. Tool box fixed nearby work centers.
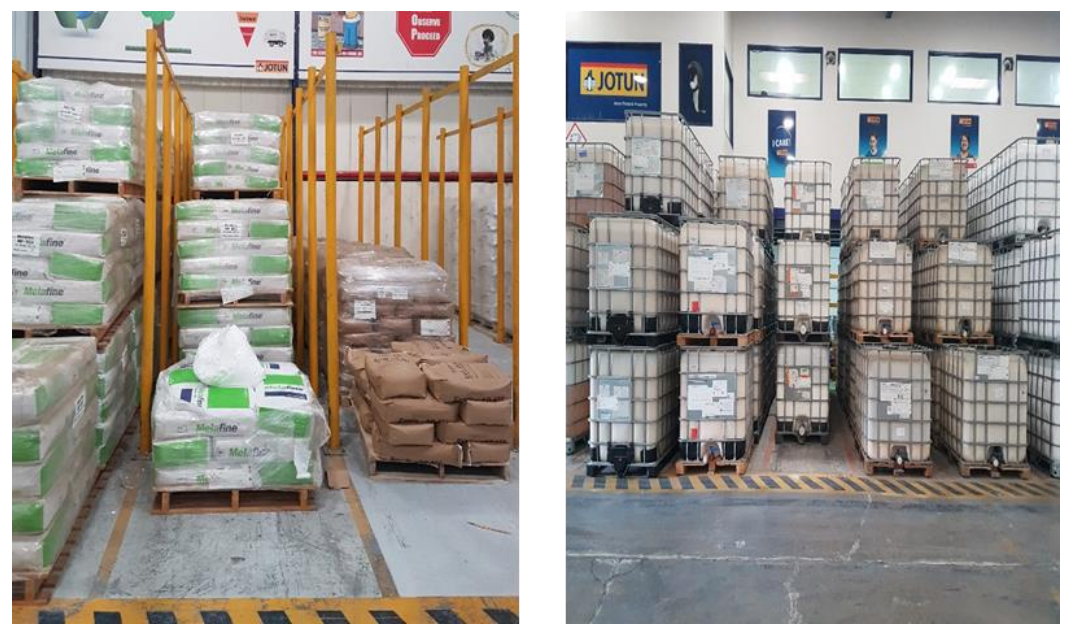

Fig. 10. Raw material reorganized in the store. 

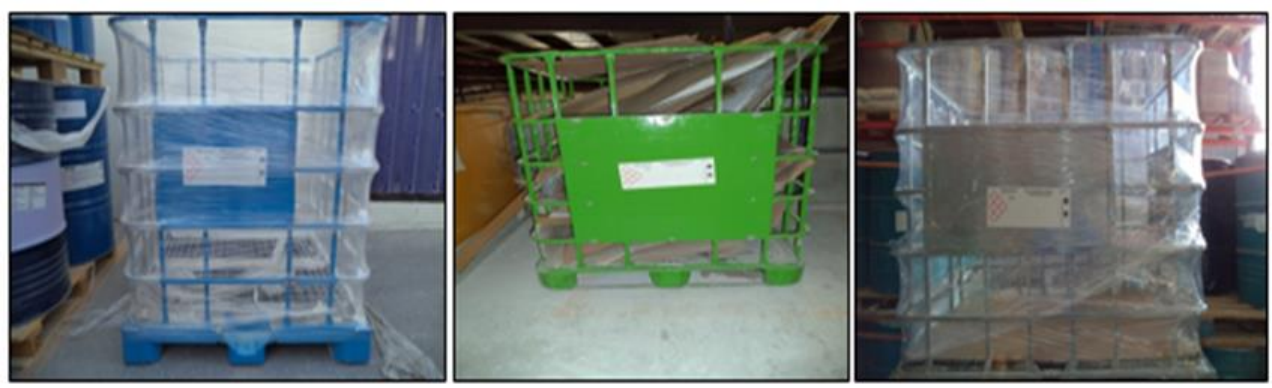

Fig. 11. Different types of trash bins (from left to right: Packing material, plastic waste, and jumbo and paper bags).



Fig. 12. Monthly waste disposal in 2017.

\subsection{The Results Obtained Using Single Minute Exchange of Dies (SMED)}

Filling of small Stock Keeping Units (SKUs) consider as a big challenge for many reasons. Lacking of fully automatic filling line, high mix of SKUs, number of workers required, ergonomics, etc. are top reasons that affect the production plan adherence and the production of small SKUs efficiency. The plan to implement the SMED concept was decided to take place on a filling line that is designed to fill three packing sizes, which are 16.2 (large), 3.6 (medium) and 0.9 (small) liters respectively. The first step to apply SMED is to sort out the internal process and external processes.

The internal process is a process or task that it can be performed only when the machine is off, while external tasks can be performed even when the machine or process is running. The idea is to convert the internal process into external process. The main area of improvement was to fabricate and design the 
parts and adjustment in a way that more efficient and with less cycle of time, the maintenance team has suggested some points of improvement as follows:

- Lid closer unit was standardized as some modification done to the holder in a way that only one holder can fit all types of lid closer.

- Marking for the level of weight was defined to adjust easily from SKU to another (Drums to gallons or small packs to drum).

- The conveyor was adjusted in a way that it can hold all the three sizes of packs with only small adjustment of the safety guard.

Tables 2 and 3, describe the changeover cycle time between all packing sizes before and after the implementation of SMED.

Table 2. Changeover cycle time before implementing SMED.

\begin{tabular}{|l|r|r|r|}
\hline \multicolumn{4}{|c|}{ Before } \\
\hline & \multicolumn{3}{|c|}{ Time (Min.) } \\
\hline Packing size & Large & Medium & Small \\
\hline Large & 0 & 20 & 30 \\
\hline Medium & 30 & 0 & 15 \\
\hline Small & 22 & 17 & 0 \\
\hline
\end{tabular}

Table 3. Changeover cycle time after implementing SMED.

\begin{tabular}{|l|r|r|r|}
\hline \multicolumn{4}{|c|}{ After } \\
\hline & \multicolumn{3}{|c|}{ Time (Min.) } \\
\hline Packing size & Large & Medium & Small \\
\hline Large & 0 & 7 & 9 \\
\hline Medium & 6 & 0 & 4 \\
\hline Small & 5 & 4 & 0 \\
\hline
\end{tabular}

The overall time for performing the changeover task from the large size to the small packing before the improvement was 22 minutes while it was reduced after the improvement took place to reach only to 5 minutes. However, the workers could not sustain changeover time of 5 minutes, after seven weeks they have successfully sustained at 9 minutes' changeover. Figure 13, shows the changeover cycle time between different packing sizes when implementing SMED process over seven weeks.

\subsection{The Results Obtained Using Work Standardization}

One of the reasons of low productivity is the high number of defected output. So, Pareto analysis implemented in the charging process to understand the causes for rejecting the batches by laboratory. Root cause analysis data for the full month gathered and analyzed for better understanding. The team stated below points as the main factors that cause the batch rejection during charging process:

- Operators skills/mistakes

-Wrong pre-weighing

- Programmable logic controller (PLC) error

- Wrong raw material label

- Others

Operators' skills/mistakes reflect any task performed by them but in a wrong manner or not as per the given instructions (e.g. mixing time, wrong addition, dissolver speed, etc.). Wrong pre-weighing means that the pre-weighing operators give wrong raw material batch or there is deviation in the raw materials given (i.e. wrong weighing of row material or not accurate weight). System's error is a reason that causes the rejection of the batch through wrong addition of raw materials, which are added through PLC system i.e. automatic addition of bulk raw materials through system and pipelines. Wrong raw material labels mean that the raw material store have pasted wrong label for a specific raw material. Others reflect any other reason that causes the defect of the batch under process such as dissolver breakdown during mixing process or any complex process. Out of 330 batches produced in a month there were 20 batches rejected by laboratory due to different reasons (see Table 4). Pareto chart, given in Fig. 14, indicates that more than $70 \%$ of defected batches were because of the operator's skills during the charging process. 
Table 4. Status of defected batches before applying work standardization technique.

\begin{tabular}{|l|l|l|}
\hline \multicolumn{3}{|l|}{ Before applying work standardization } \\
\hline Charging process & $\begin{array}{l}\text { Defects } \\
\text { (in batches) }\end{array}$ & Defects (\%) \\
\hline Operator mistake & 14 & $70 \%$ \\
\hline Wrong pre-weighing & 2 & $10 \%$ \\
\hline PLC/System error & 1 & $5 \%$ \\
\hline Wrong label for RM & 1 & $5 \%$ \\
\hline Others & 2 & $10 \%$ \\
\hline & 20 & $100 \%$ \\
\cline { 2 - 3 } & &
\end{tabular}

A month after the training session was finished, it showed that the number of defected batches caused due to operator's skills/mistakes reduced to reach only six batches out of 322 batches. (Table 5 and Fig. 15).

Table 5. Status of defected batches after applying work standardization technique.

\begin{tabular}{|l|l|l|}
\hline \multicolumn{3}{|l|}{ After applying work standardization } \\
\hline Charging process & $\begin{array}{l}\text { Defects } \\
\text { (in batches) }\end{array}$ & Defects (\%) \\
\hline Operator mistake & 6 & $43 \%$ \\
\hline Wrong pre-weighing & 2 & $14 \%$ \\
\hline PLC/System error & 1 & $7 \%$ \\
\hline Wrong label for RM & 2 & $14 \%$ \\
\hline Others & 3 & $21 \%$ \\
\hline & 14 & $100 \%$ \\
\cline { 2 - 3 }
\end{tabular}

Cycle Time (Min)

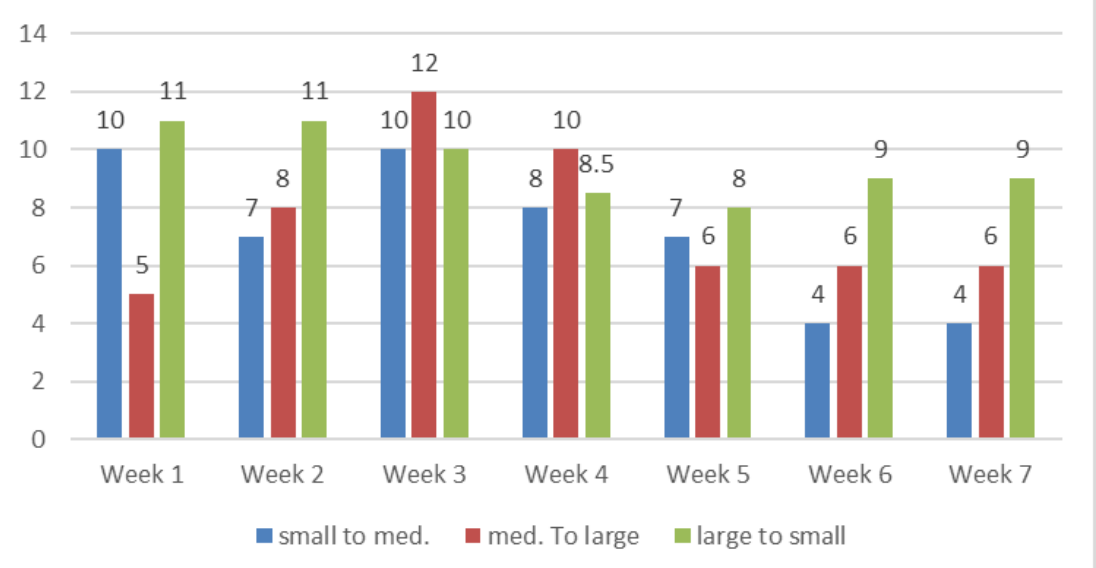

Fig. 13. Cycle time for changeover between different packing sizes.

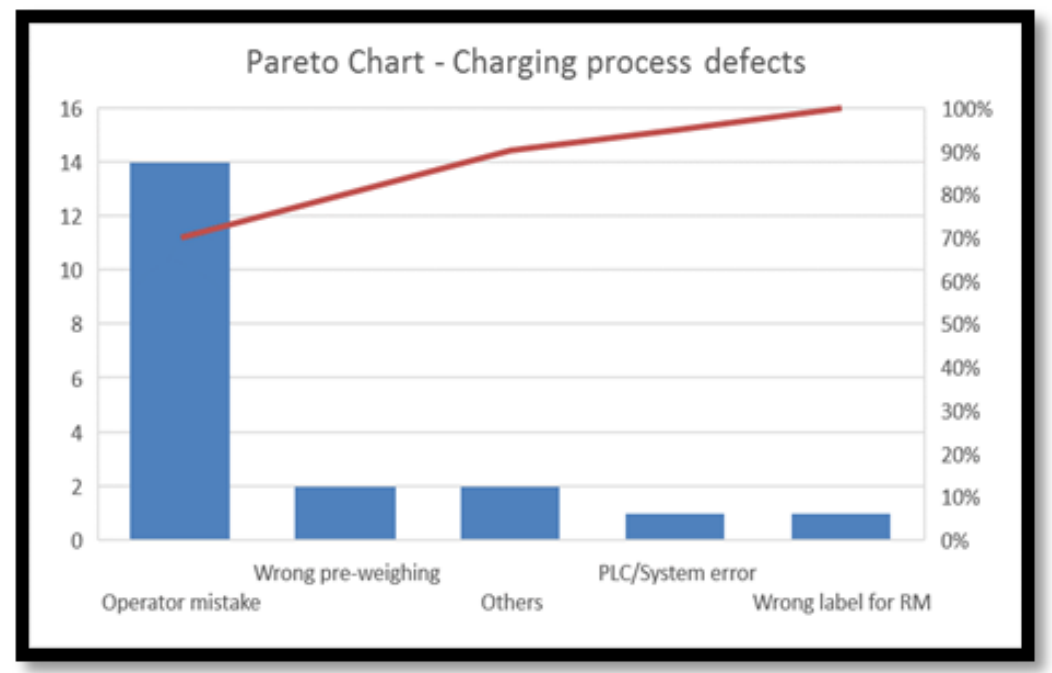

Fig. 14. current Pareto chart for the charging process defects. 


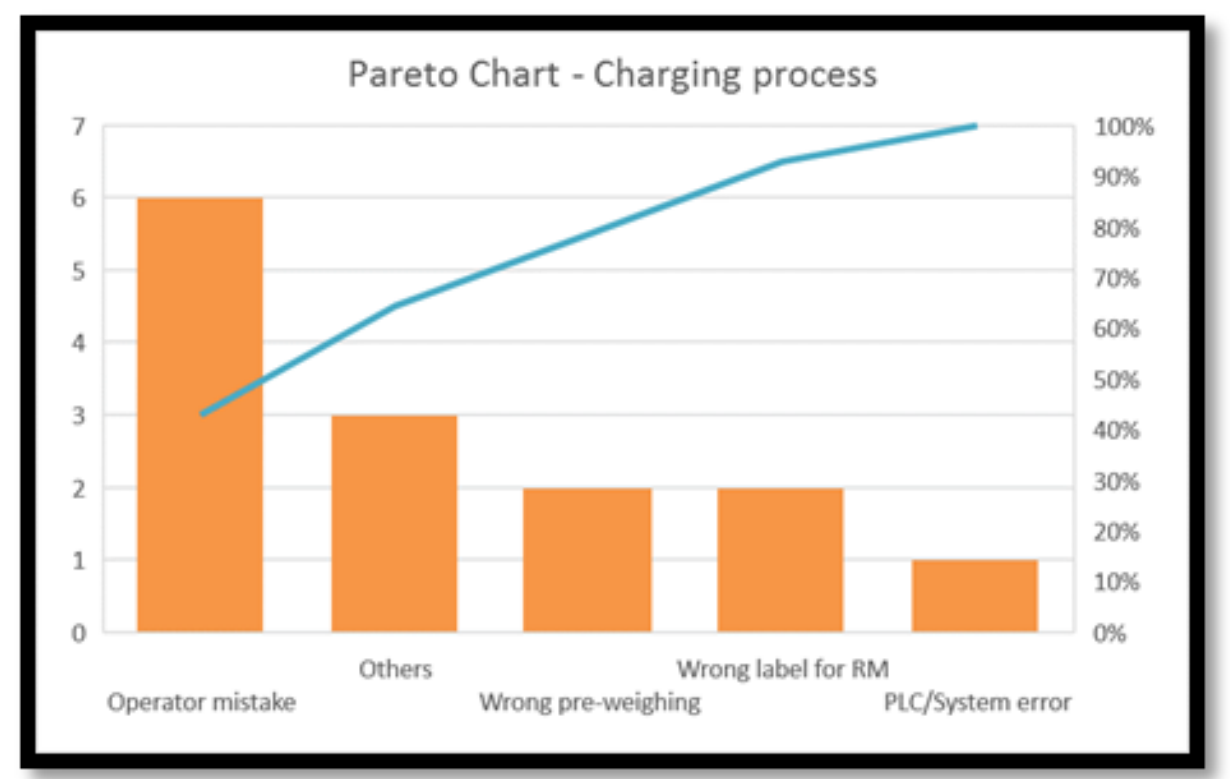

Fig. 15. Pareto chart for the charging process defects after work standardization.

\subsection{The Results Obtained using KANBAN Technique}

In paint manufacturing, there are fast moving and slow moving liquid paint products. In the paint company under study, the liquid paint product, say product (A) is defined as fast moving product, which is contributed by $55 \%$ of the total production annually. This type of products uses several raw materials for manufacturing. The raw materials used to manufacture the product (A) can be categorized as raw material that is coming from supplier directly and can be used as it is or as raw material that is produced in the factory as a semi-finish product to be used for the manufacturing this product (A). The semi-finish product is stored in Intermediate Bulk Containers (IBCs), a big PVC tank having a capacity of 1000 Liter.

The production efficiency is monitored by the production engineers and coordinators. However, the reports show that raw material shortages are a bottleneck in the production department therefore, the team has investigated the reasons behind the shortages and it was found that migration of raw material and fluctuation of the lead-time from suppliers is the most causes of the shortages of the raw material. In fact, the engineers have found that shortages of semi-finish product have a big contribution in the total shortages occurred during the year. Further investigation concludes that the shortages of the semi-finish raw material is not because of the unpredicted increase of the lead time, neither the delay from the custom nor from the inspections but it was because of lack of controlling of the stock of the semi-finish product. The raw material staff are busy with the raw material follow up and has no clue with the semi-finish raw material. The production team is not familiar of controlling of stock of raw material and thus leading to shortages of such semi-finish raw material.

A brain storming session conducted with the production operators, supervisors, raw material storekeeper and engineers to find best possible solution that can eliminate the sudden shortages of the semi-finish raw material. Applying production Kanban will have the 
potentials to better control the stock of the semi-finished raw material, the team concluded. To do this, production engineers calculated the number of Kanban that ensures no shortage would occur. The idea is to make it visible and easily understand by the shop floor operators. Two lean techniques were used to help in this matter, Production Kanban and work standardization.

Here, production Kanban will be handled. The team used the equation shown below to determine the number of Kanban required to insure there will be no stoppage of production due to yellow oxide shortage.

Number of Kanbans/Containers $=\frac{\text { Demand during lead time }+ \text { safety stock }}{\text { Container size }}$

Where demand during lead time = consumption per day multiply by lead time to replenish an order.

Due to the high uncertainty for this item, the safety stock decided to be $20 \%$ of the demand during the lead-time. One IBC (container) can take up to 500 Liter of yellow oxide. The daily average consumption of Yellow oxide is 370 Liters and the lead-time to produce an order of yellow oxide is 6 working days. The calculations show that $5.77 \simeq 6$ containers/Kanban $\left(500^{*} 6=3000\right.$ Liters batch) will be the ideal number of Kanban's/Containers.

Since the production, process of yellow oxide is complex and it takes one full day of production. Yellow oxide is produced on the same dissolver that used to manufacture many different products that required by customers (Finish goods products). The engineers decide to make a signal Kanban systems that can store up to 6 containers (i.e. pallets). The Kanban area is consisting of 6 pallets. One container will be placed in the manufacturing floor, where it pre-weighted by the manufacturing operators to produce another product. Once the container is fully consumed, the manufacturing operator will inform the forklift operator to bring a new container from the Kanban area. The forklift operator will go to the Kanban area and will take one container and place it in the manufacturing floor. This process will be repeated until there remains only one container in the Kanban. Once the forklift goes to bring the 5th container, he will see a signal in the Kanban area (painted in red) that will indicate to the production planner to place an order for the yellow oxide. Six days is the time required to refill the Kanban area with full 6 containers with a batch size of 3000 liters and it's the average consumption rate for the remaining container, i.e. the last container that remains for use will be sufficient to run the production for 6 days, which is the lead time to manufacture the yellow oxide and re fill the Kanban fully.

As mentioned earlier, one of the bottlenecks in the pre-weighing process is the number of the pre-weighed batches, which will affect the charging process if the next pre-weighed batch is not ready. Product (A) which is $55 \%$ of total Jeddah factory output is being produced in 5 different production lines which are dedicated for this product. Any delay in the pre-weighing process will affect the charging efficiency and thus can delay the manufacturing process and accordingly the customer demand. The root cause behind the delay of the pre-weighing process is the sudden order of the next pre-weighed batch from the charging operator where the shop order is still not yet submitted to the pre-weighing operator or because there is an urgent order from a customer and the shop order is still not yet handled to the pre-weighing store. There are three standard batch sizes for five different production lines. Table 6 , illustrates each production line batch size. 
Table 6. The different batch sizes according to the production line.

\begin{tabular}{|l|r|r|r|r|r|}
\hline & \multicolumn{5}{|c|}{ Batch size for each production line } \\
\hline Production line & 1 & 2 & 3 & 4 & 5 \\
\hline Standard size & 4400 & 4400 & 6650 & 8022 & 8022 \\
\hline
\end{tabular}

As described in the table above, there is only 3 different sizes of pre-weighing batches. Production lines 1 and 2 have the same batch size and thus the pre-weighing materials are the same for both tanks (i.e. the weight of the raw material for both production lines is the same and it can be used also for production line two as the product is one and the size is the same). The same concept is for production line four and five. The team has decided to make a super market Kanban for this product aligned for the 5 production lines. Racks has been installed and divided into three columns, where each column allocated to standard batch size, which are 4400, 6650 and 8022 liters. The idea is to let the pre-weighing operators fill the Kanban with no shop orders attached. This super market Kanban will make sure that the pre-weighed batches are always available to start the charging process. The shop order papers will be with the charging operators instead of being handed to the pre-weighing operators (Fig. 16). Currently the number of pre-weighed batches for is equal to 19 batches per shift and after the implementation of the super market Kanban the pre-weighing operator were able to pre-weigh total of 30 batches where the waiting time has been reduced to reach only 2 minutes. Production stoppage due to pre-weighing process was reduced to reach only 3 times for a full month and the process mapping for the preweighing stage further improved to be as described in Fig. 17.

\section{Discusstion}

Applying lean principles and tools in manufacturing facilities is a quick win strategy especially if it is newly applied (i.e. first time for application in a certain company). As a conclusion, the suggested four Lean
Manufacturing (LM) tools applied throughout the manufacturing process made significant difference. These four tools named: 5S, SMED, work standardization and Kanban achieved the study objectives. The study dealt with the three main processes in paint manufacturing which are pre-weighing process, charging process and filling process. The four LM techniques implemented in all the three processes simultaneously.

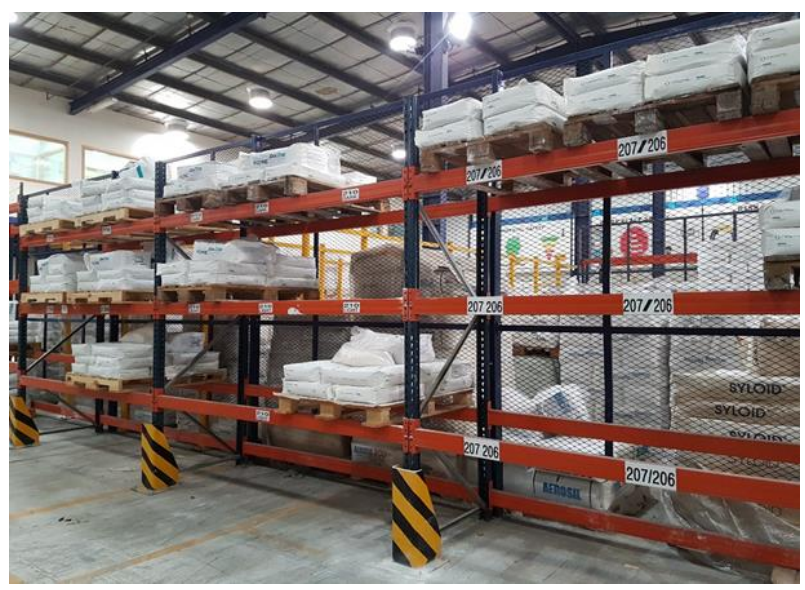

Fig. 16. Super market Kanban.

\section{Pre-Weighing Process}

Since the pre-weighing process is the first step in the real painting manufacturing process and thus, any improvement in this stage will directly improve the next processes that are charging and the filling process. Supermarket Kanban and 5S techniques have significantly improved the pre-weighing process. Organizing the workplace (5S) through creating dedicated (marked) areas for the weighing scales, trolleys, stackers, RM, etc. reduced the average pre-weighing time of a single batch by $36 \%$ (i.e., from 25 minutes to 16 minutes). The supermarket Kanban played a massive rule in increasing the productivity. The pre-weighing process daily output increased by $57 \%$ and reached to 30 batches instead of 19 batches daily. Below points illustrate the improvement clearly:

- Pre-weighing Cycle time per batch: $16 \mathrm{~min}$ 
- Number of batches pre-weighed per shift: 30 batches

- Total waiting time (non-value added): $2 \mathrm{~min}$

- Total Movement time (non-value added): 3 $\min$

- Total non-value added time: 5 min

- Total value added time: $11 \mathrm{~min}$

\section{Charging Process}

The $5 \mathrm{~S}$ or workplace organization technique improved the process efficiency and reduced the time of the tasks involved in the production process. The main contribution in the charging process attained by the implementation of work standardization and the Pareto chart where the number of the defected batches due to operators' mistake has been reduced from 14 to 6 that means reduction by $57 \%$. Starting the pre-weighing process with supermarket Kanban for the fastest moving products increased the productivity of the charging process as the operators will not wait for the pre-weighing next batch due to delay from the planner or the workload. The average charging time for the fastest moving products was 150 minutes and after the implementation of $5 \mathrm{~s}$ and the Kanban system, it has been reduced to 122 minutes (i.e., saving time by $19 \%$ ).

\section{Filling Process}

Applying 5S Technique in the filling area decreased the movement of the operators to remove the pallets and thus, it reduced the average filling time. In fact, the cleaning of the machines and filling lines including the conveyors during the preventive maintenance are improved and the down time is reduced significantly. In addition, SMED technique has increased the adherence to the daily production plan. Adherence to the daily production plan is calculated by activity (i.e. the planners will assign for each work centers a target that is based on the product and the time associated for manufacturing so if the production team completes the target for all the work centers they can get $100 \%$ adherence to the plan). Figure 18 shows the adherence to the daily production plan for Nov. 2017 after implementing SMED and 5S techniques.

\section{Waste Management}

Using 5 s technique to control the waste handling and treatment reduced the cost more than expected. In fact, the non-hazardous waste and the hazardous waste have been reduced by $85 \%$ and $53 \%$ respectively (Fig. 19).

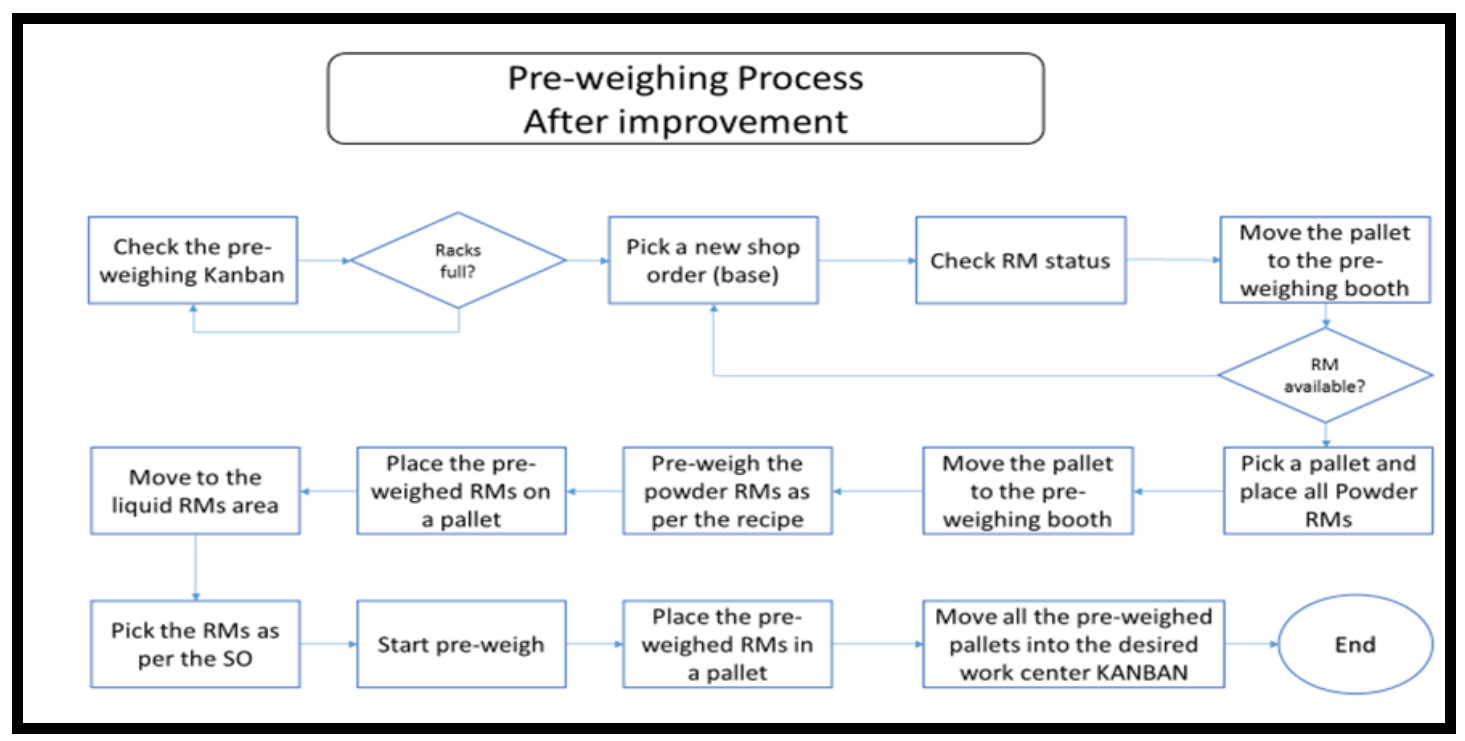

Fig. 17. Improved process mapping for the pre-weighing process. 


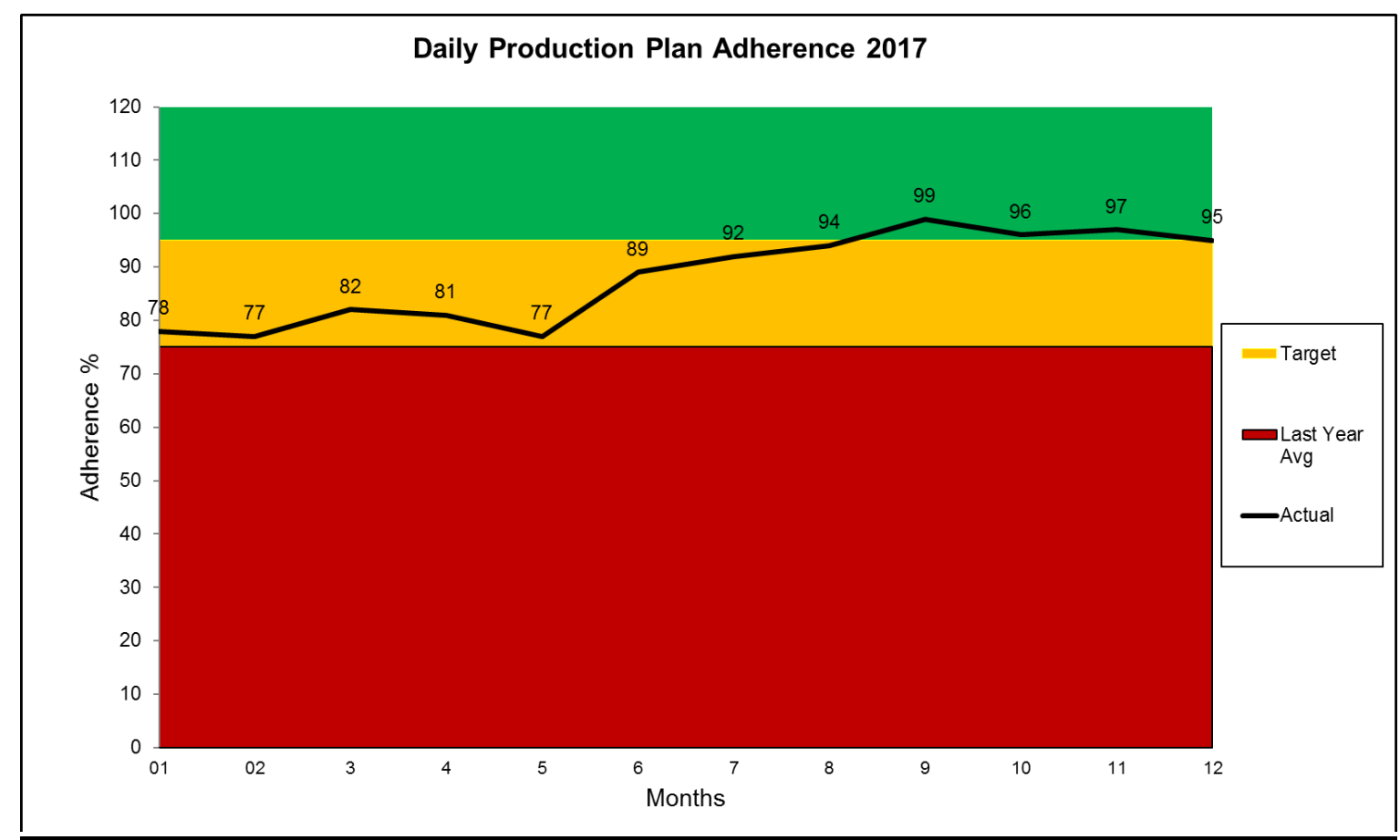

Fig. 18. Production plan adherence.
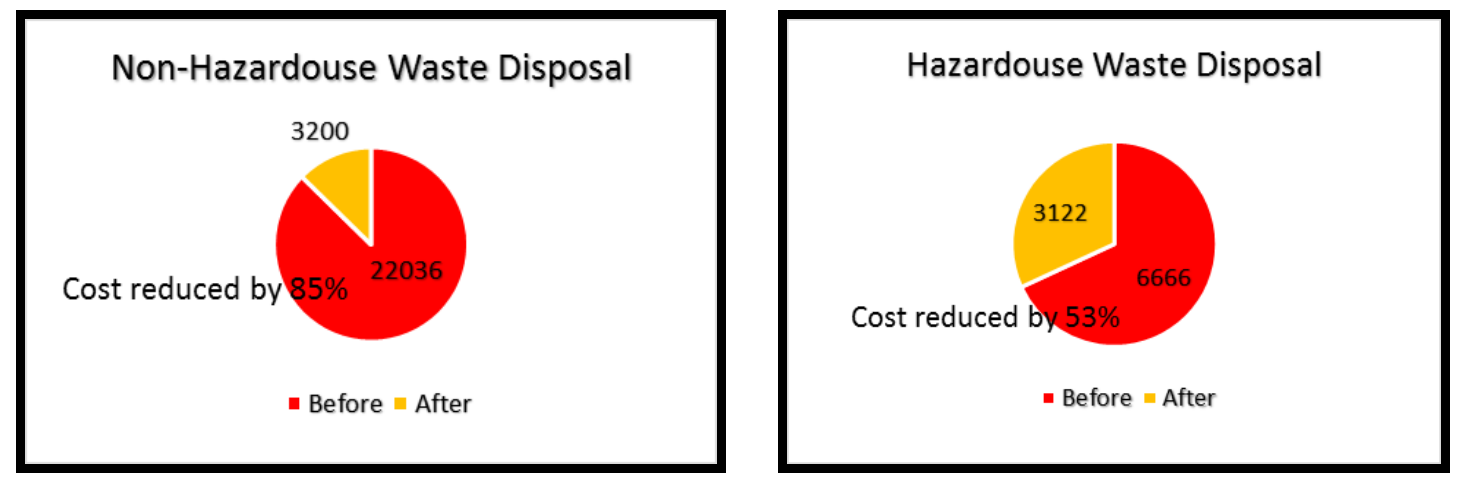

Fig. 19. Waste disposal before and after the 5 s technique.

The implementation occurred only in Dec.2017 to test the impact and it proves that the impact was significant. The overtime associated for each month has been reduced as a result of implementing the LM techniques (Fig. 20).

\section{Conclusion}

Understanding the manufacturing process deeply is a vital to track the bottlenecks and then the area of improvements. Lean manufacturing principles proofs its ability to increase the productivity without the need to spend much money as its more of administrative tools and solutions. Being able to control and minimize the waste using a technique like $5 \mathrm{~s}$, which not required big budget to implement, is a key solution during recession. The benefit of techniques like fishbone analysis, SMED, value stream mapping, etc. not only in increasing the productivity and identifying the area of weakness, in fact, theses techniques will enhance the team work and will increase the engagement level of the people which itself will motivate them and give them a space to innovate. 
Meeting the customer expectations during recession is important and will insure more market share, where many rivals will suffer in meeting the customers' demands if not responding quickly and effectively and lean manufacturing principles have all the abilities to do so.

\section{Future Work}

This study has proven that applying the Lean Manufacturing (LM) principles is a key success factor in achieving high productivity rates and overcomes the productions bottlenecks. However, there are some recommendations and suggestions that if applied will further enhance the productivity and identify more bottlenecks. Applying 7s, which is the developed technique of $5 \mathrm{~s}$, will enhance further the impact of the technique. Including the laboratory stage will further increase the productivity and reduce the lead time. Future status of VSM will could better point out the improved area. As human, the tendency to resist any new change is natural and therefore it should be tracked properly prior implementing any new technique or procedure by introducing the change to the people and letting them understand the change before acting it.

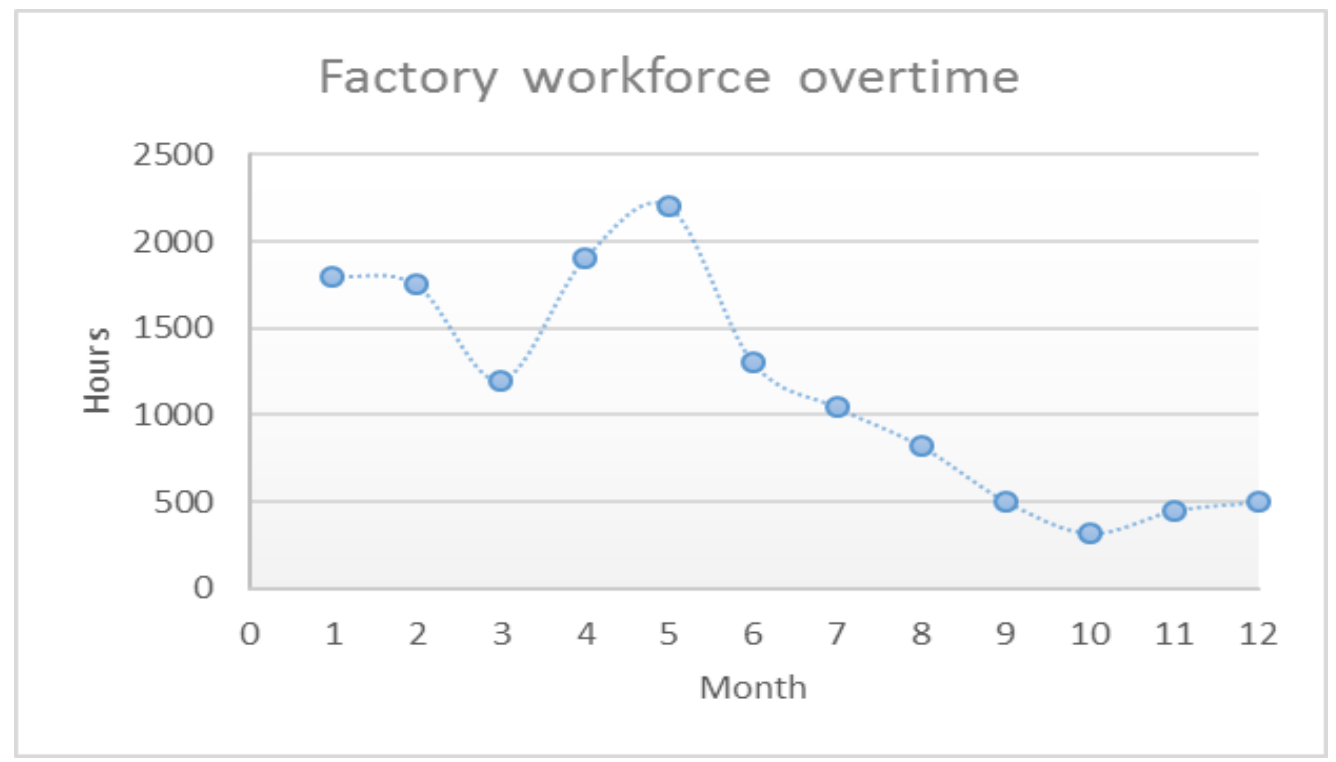

Fig. 20. Overtime trend while implementing LM tools.

\section{References}

[1] Tortorella, G. and Fogliatto, F., Implementation of lean manufacturing and situational leadership styles: An empirical study, Leadership \& Organization Development Journal, 38 (7): 946-968 (2017).

[2] Krafcik, J. F., Triumph of the lean production system. Sloan Management Review, 30(1): 41-52 (1988).

[3] Wang, J. X., Lean Manufacturing: Business bottomline based. Boca Raton, CRC Press, $1^{\text {st }}$ edition, Florida, Boca Raton (2011).

[4] Bhasin, S., Lean management beyond manufacturing: A holistic approach. Springer-Cham (Switzerland), pp: 149-160 (2015).
[5] Puvanasvaran, A. P., Managing waste elimination database in Lean manufacturing: Improve problem solving capability, American Journal of Engineering and Applied Sciences, 7 (2): 271-281 (2014).

[6] Wilson, L., How to Implement Lean Manufacturing, McGraw-Hill Education, $1^{\text {st }}$ edition, US, NY, PP 73128 (2015).

[7] Ab Rahman, M. N., Khamis, N. K., Zain, R. M., Deros, B. M. and Mahmood, W. H. W., Implementation of $5 \mathrm{~S}$ practices in the manufacturing companies: A case study. American Journal of Applied Sciences, 7(8): 1182-1189 (2010).

[8] Ghodrati, A. and Zulkifli, N., The Impact of 5S 
Implementation on Industrial Organizations' Performance. International Journal of Business and Management Invention, 2(3), 43-49 (2013).

[9] Sajan M.P., Shalij P.R., Ramesh A. and Biju Augustine P., Lean manufacturing practices in Indian manufacturing SMEs and their effect on sustainability performance, Journal of Manufacturing Technology Management, 28 (6) : 772-793 (2017).

[10] Sabadka, D,. Molnar, V. and Fedorko, G., The use of lean manufacturing techniques - SMED analysis - to optimization of the production process, Advances in Science and Technology Research Journal, 11 (3): 187195 (2017).

[11] Madhav, R., Marnewick, A., Nel, H. and Pretorius, J. H., Managing Changeover Waste in Manufacturing Plants when Using Single Minute Exchange of Dies, IEOM Society International, Morocco April (2016).

[12] Bajpai, J. D., SMED (single-minute exchange of die) methodology in garment manufacturing industry: Case study in reducing style change over time. In
Proceedings of the 5th International \& 26th All India Manufacturing Technology, Design and Research Conference (AIMTDR 2014), Guwahati, India, pp: 1214) (2014).

[13] Lucherini, F. and Rapaccini, M., Exploring the Impact of Lean Manufacturing on Flexibility in SMEs, Journal of Industrial Engineering and Management, 10(5): 919945 (2017).

[14] Dennis, P., Lean Production simplified: A Plainlanguage Guide to the World's Most Powerful Production System, Productivity Press, 3rd Edition, pp:102-110 (2015).

[15] Corona, E. and Pani, F. E., A review of lean-kanban approaches in the software development. WSEAS Transactions on Information Science and Applications, 10(1): 1-13 (2013).

[16] Reddy, A. (2015). The Scrumban [r] evolution: Getting the Most Out of Agile, Scrum, and Lean Kanban. Pearson Education, US, Indiana (2015). 


\section{تطبيق أساليب التصنيع الخالي من الهدر فى شركة لتصنيع الدهان: حالة دراسية}

\section{أحمد باديب، و رضا عبد العال، و عبد الله بافيل}

\section{قسم الهندسة الصناعية، كلية الهندسة، جامعة الملك عبد العزيز، جدة، المدلكة العربية السعودية}

الدستخلص. نتيجة للانكماش الاقتصادي الحاصل في المملكة العببية السعودية، بدأت شركات التصنيع بالتفكير في تقليل التكلفة

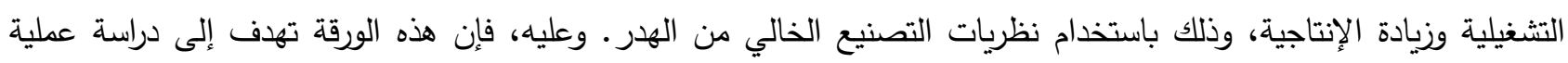

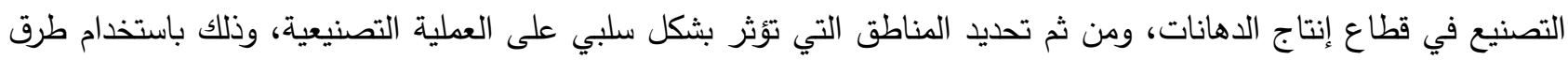

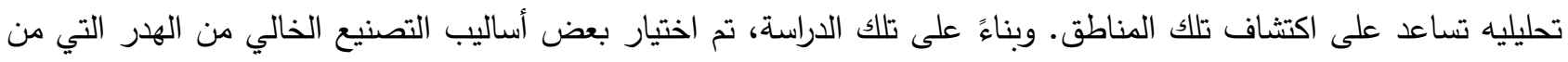

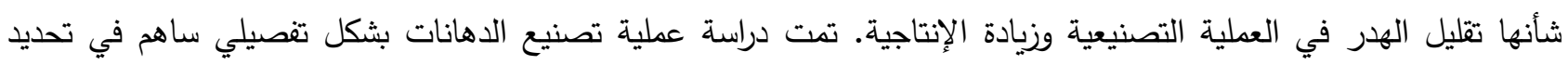

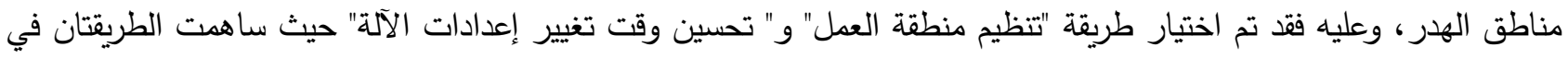
زيادة الإنتاجية اليومية، وتم تقليل وقت التغيير بنسبة وصلت إلى

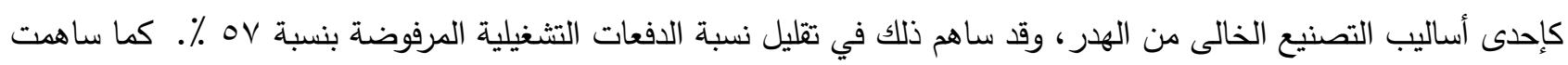

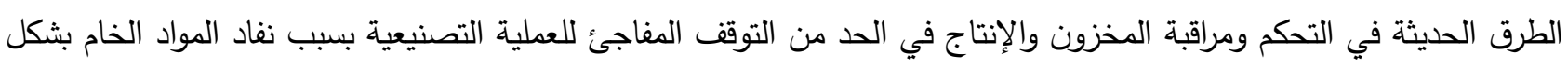

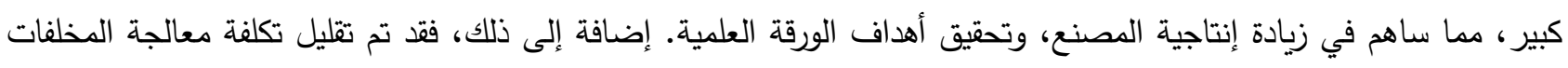

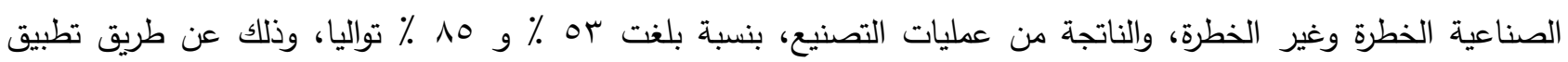

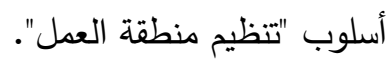

كلمات منتاحية: تصنيع الطلاء، التصنيع الخالي من الهدر، دقيقة واحدة لتبادل القوالب، تقنية تنظيم مكان العمل، تحسين وقت

$$
\text { تغيير إعدادات الآلة. }
$$


